BMJ Open Sport \& Exercise Medicine

\title{
Self-reported worst injuries in women's Australian football identify lower limb injuries as a prevention priority
}

\author{
Lauren V Fortington, Alex Donaldson, Caroline F Finch
}

To cite: Fortington LV, Donaldson A, Finch CF. Selfreported worst injuries in women's Australian football identify lower limb injuries as a prevention priority. BMJ Open Sport Exerc Med 2016;2:e000112. doi:10.1136/bmjsem-2016000112

- Prepublication history and additional material is available. To view please visit the journal (http://dx.doi.org/ 10.1136/bmjsem-2016000112).

Accepted 11 March 2016

\section{CrossMark}

Australian Collaboration for Research into Injury in Sport and its Prevention (ACRISP), Federation University Australia, Ballarat, Victoria, Australia

\section{Correspondence to} Dr Lauren V Fortington; I.fortington@federation.edu. $\mathrm{au}$

\section{ABSTRACT}

Background: Increasing participation by women in Australian football (AF) has made understanding their specific injury prevention needs a priority. In other sports, men and women have different injury profiles. This study aims to provide the first overview of selfreported injuries in women's AF.

Methods: Nationwide survey of women aged 17+ years who played in an AF competition was conducted following the 2014 playing season. The players' selfreported worst injury from the 2014 season is presented according to injury type, body part injured, treatment sought and games/training missed.

Results: Three-quarters of 553 respondents $(n=431$, $78 \%)$ reported at least 1 injury. Over half $(n=235$, $55 \%$ ) of injuries were to the lower limb. Ankle ligament tears/sprains ( $n=50,12 \%$ of all injuries) and knee ligament tears/sprains $(n=45,10 \%)$ were most frequent lower limb injuries reported. Two-thirds (65\%) of all lower limb injuries led to at least 1 missed game. Of 111 (26\% of all injuries) upper limb injuries reported, over half $(n=57,62 \%)$ were to the hand/fingers/thumb, including fractures ( $n=28,6 \%$ of all injuries), ligament tears/sprains $(n=18,4 \%)$ and dislocations $(n=11,3 \%)$. Half of the upper limb injuries (51\%) resulted in players missing matches/training.

Conclusions: The most frequent self-reported worst injuries for women playing $A F$ were joint damage to the ankle and knee. A prospective injury study is needed to confirm the causes and rate of these lower limb injuries to identify the most suitable prevention interventions.

\section{INTRODUCTION}

Australian football (AF) is one of the most popular team sports in Australia. The sport features fast-paced play, full body contact including tackling and bumping, frequent jumping/landing, sprinting/acceleration and changes of direction. These characteristics place players at a relatively high risk of sustaining an injury when participating, particularly in competitive games. $^{1-3}$ The most common AF injuries are lower limb muscle strains and superficial injuries (eg, bleeding, lacerations) in community levels of play,

\section{Summary of new findings}

- The most frequent self-reported worst injuries sustained by women in one season of Australian football were ankle and knee ligament tears/ sprains.

- Self-reported injuries had a substantial impact on players in terms of impaired participation, pain, missed games/training and requiring medical treatment.

- A comprehensive prospective injury study in women's Australian football is warranted to provide more robust data on injury rates to build from the priority injuries identified.

- The priorities identified in this study enable Australian football agencies to begin to target injury prevention measures specifically for women.

upper limb fractures in medically treated community footballers, and calf/groin/quadriceps strains in elite professional players. ${ }^{2}$ Knee injuries are a particular problem owing to their high burden, often requiring players to have time-off from sport and medical treatment. 4 Prevention strategies targeting priority lower limb injuries have been developed to address these key injuries. ${ }^{5-7}$

To date, all of the research and preventive efforts in AF have been concerned with men. Recently, there has been huge growth in the number of women and girls playing AF. In 2014, almost 200000 women and girls took part in registered competitions, rising to over 284000 in $2015 .^{89}$

In other football codes and team ball sports, the risk of injury and the type of injuries sustained differ between men and women, particularly in relation to concussion and knee injuries. ${ }^{10-13}$ To date, there has been no published reporting of injuries in women who play AF, at any level of play.

To continue to promote the game and the associated health and social benefits of participating in a team sport, it is important to consider sport safety policies and practices in 
$\mathrm{AF}$ that are relevant for women. In 2014, the Australian Football League (AFL), the peak body for the sport, initiated the FootyWISE (Women's Injury Surveillance Extension) project to provide the first systematic profile of AF-related injuries in women. The aim of this study was to undertake a nationwide survey of self-reported injuries in adult, women, AF participants as a first step towards identifying and describing key injuries to target in future prevention efforts.

\section{METHODS}

\section{Ethics}

The project was approved by the Federation University Human Research Ethics Committee (A14-083).

\section{Setting and inclusion criteria}

A self-report, online injury survey was undertaken at the end of the $2014 \mathrm{AF}$ season. All women, aged 17+years, who were formally registered to play in a women's AF competition, at any level of play, in one of eight Australian States/Territories in 2014 were eligible for inclusion. There were 4996 women aged 19+ years registered during the 2014 season (registration data were not available for players aged 17+ years due to competition structures). Players were included whether or not they reported participating for a full season and whether or not they reported sustaining an injury.

\section{Survey development}

Survey questions $(\mathrm{n}=23)$ were drawn from a previously validated survey of $\mathrm{AF}$ injuries in adult men, ${ }^{14}$ modified for the current study. Four screening questions at the beginning of the survey ensured that only women (not men) players (not coaches, officials or volunteers) aged $17+$ years were included. Respondents were then asked eight general retrospective questions about their participation in AF (why they played, how often they played, where they played, etc). Finally, up to 11 questions were asked about the respondents' injury history for the 2014 season, with the total number of injury-focused questions dependent on responses.

Injury was defined as 'any physical problem that may have caused pain, bleeding, loss of movement or loss of function in a part of your body'. The injury may or may not have resulted in the player leaving the field, missing a game or requiring treatment. Specific injury details were sought on the players' self-judged worst/most severe injury of the 2014 season. Information about the impact of the worst injury in terms of participation and treatment required was also requested. Injury types and body region injured, based on definitions from the Australian Sports Injury Data Dictionary, underpinned the injury questions and coding. ${ }^{15}$

Each survey question asked respondents to choose one answer from a number of closed options. An option for 'other, please provide details' was available for most questions. For the question on treatment received for the worst injury, participants could choose more than one answer. The survey questions and response choices are available in online supplementary appendix A.

\section{Procedure}

The survey was administered using the online software SurveyMonkey. The AFL emailed a direct invitation to participate in the research to all eligible players at the end of the 2014 regular playing season. Participants could access the online survey via a link, kept live for one calendar month (September 2014). The link was also disseminated widely through social media (Facebook and Twitter), with an email reminder also sent by the AFL at the mid-point of the survey period.

\section{Analysis}

A descriptive analysis is presented with frequencies and proportions reported for all respondents for general questions and injured respondents for injury-based questions. Some responses were grouped to ensure sufficient numbers for anonymity and practicality in presentation. Data were managed and analysed using Microsoft Excel, SPSS V.21 and OpenEpi: Open Source Epidemiologic Statistics for Public Health.

\section{RESULTS}

\section{Survey participants}

A total of 596 people initiated responses to the survey, of which 553 were eligible for inclusion. This corresponds to $11 \%$ of the registered players. Forty-three respondents were excluded, including 5 men, 22 who did not state their gender, 15 coaches/trainers/volunteers and 1 person who did not consent to participate. Table 1 shows the characteristics and participation profile of all included survey respondents. Based on a comparison of CIs, there were no significant differences in respondents who reported themselves as injured or not injured.

\section{Overall number and types of injuries}

Over three-quarters $(78 \%, \mathrm{n}=431)$ of respondents reported being injured during the 2014 season, with two-thirds of these $(67 \%)$ indicating that they had sustained more than one injury. Most injuries (75\%) occurred during games, rather than training.

Respondents were asked to provide details of their selfjudged worst/most severe injury for the season (table 2). The most common injury types reported were joint damage $(45 \%)$, muscle strains $(22 \%)$ and fractures $(15 \%)$.

Over half $(55 \%, \mathrm{n}=235)$ of all worst injuries involved the lower limb, with half of these $(29 \%$ of all injuries, $\mathrm{n}=127$ ) involving joint damage. Specifically, lower limb joint damage included ankle ligament sprains/tears ( $\mathrm{n}=50,12 \%$ of all injuries), knee ligament tears/sprains $(\mathrm{n}=45,10 \%$ of all injuries) and knee cartilage injuries ( $\mathrm{n}=13,3 \%$ of all injuries). Muscle strains involved the upper leg/thigh ( $\mathrm{n}=25,6 \%$ of all injuries) and lower $\mathrm{leg} /$ calf $(\mathrm{n}=24,6 \%$ of all injuries). Most $(65 \%)$ lower 
Table 1 Characteristics of all included $(n=553)$, injured $(n=431)$ and non-injured $(n=122)$ respondents from senior women's Australian football

\begin{tabular}{|c|c|c|c|c|c|c|c|c|c|}
\hline & \multicolumn{3}{|c|}{ All players $(n=553)^{*}$} & \multicolumn{3}{|c|}{ Injured $(n=431)$} & \multicolumn{3}{|c|}{$\begin{array}{l}\text { Non-injured or not stated } \\
(n=122)^{*}\end{array}$} \\
\hline & $\bar{n}$ & Per cent & $95 \% \mathrm{Cl}$ & $\bar{n}$ & Per cent & $95 \% \mathrm{Cl}$ & $\bar{n}$ & Per cent & $95 \% \mathrm{Cl}$ \\
\hline \multicolumn{10}{|l|}{ Age group (years) } \\
\hline $17-20$ & 137 & 24.8 & (21.4 to 28.5$)$ & 101 & 23.4 & (19.7 to 27.7$)$ & 36 & 29.5 & (22.1 to 38.1$)$ \\
\hline $21-24$ & 120 & 21.7 & (18.5 to 25.3$)$ & 96 & 22.3 & (8.6 to 26.4$)$ & 24 & 19.7 & (13.6 to 27.6 ) \\
\hline $25-29$ & 156 & 28.2 & (25.6 to 32.1 ) & 121 & 28.1 & (24.0 to 32.5$)$ & 35 & 28.7 & (21.4 to 37.3 ) \\
\hline $30-34$ & 89 & 16.1 & (13.3 to 19.4$)$ & 69 & 16.0 & (12.9 to 19.8$)$ & 20 & 16.4 & (10.9 to 24.0$)$ \\
\hline 35 and older & 51 & 9.2 & (7.1 to 11.9$)$ & 44 & 10.2 & (7.7 to 13.4$)$ & 7 & 5.7 & (2.8 to 11.4$)$ \\
\hline Missing & 0 & & & 0 & & & 0 & & \\
\hline \multicolumn{10}{|l|}{ State/territory } \\
\hline Victoria & 245 & 45.1 & (41.0 to 49.3 ) & 184 & 42.7 & (38.1 to 47.4 ) & 61 & 54.5 & (45.3 to 63.4 ) \\
\hline New South Wales & 81 & 14.9 & (12.2 to 18.2$)$ & 71 & 16.5 & (13.3 to 20.3 ) & 10 & 8.9 & (4.9 to 15.7$)$ \\
\hline Queensland & 70 & 12.9 & (10.3 to 16.0$)$ & 63 & 14.6 & (11.6 to 18.3 ) & 7 & 6.3 & (3.1 to 12.3 ) \\
\hline Other state/territory & 147 & 27.1 & (23.5 to 31.0$)$ & 113 & 26.2 & (22.3 to 30.6$)$ & 34 & 30.4 & (22.6 to 39.4$)$ \\
\hline Missing & 10 & & & 0 & & & 10 & & \\
\hline \multicolumn{10}{|l|}{ Number of seasons played } \\
\hline 1st season & 134 & 24.4 & (21.0 to 28.1$)$ & 113 & 26.2 & (22.3 to 30.6$)$ & 21 & 17.6 & (11.8 to 25.5$)$ \\
\hline 2-3 seasons & 178 & 32.4 & (28.6 to 36.4$)$ & 141 & 32.7 & (28.5 to 37.3 ) & 37 & 31.1 & (23.5 to 39.9 ) \\
\hline $4-5$ seasons & 88 & 16.0 & (13.2 to 19.3$)$ & 68 & 15.8 & (12.6 to 19.5$)$ & 20 & 16.8 & (11.2 to 24.5$)$ \\
\hline 6 seasons or more & 150 & 27.3 & (23.7 to 31.1 ) & 109 & 25.3 & (21.4 to 29.6$)$ & 41 & 34.5 & (26.5 to 43.4$)$ \\
\hline Missing & 3 & & & 0 & & & 3 & & \\
\hline \multicolumn{10}{|l|}{ Main reason for playing } \\
\hline I just love footy - it is a great game to play. & 279 & 50.7 & (46.6 to 54.9$)$ & 212 & 49.2 & (44.5 to 53.9$)$ & 67 & 56.3 & (47.3 to 64.9$)$ \\
\hline I like being part of a team and working together. & 87 & 15.8 & (13.0 to 19.1$)$ & 68 & 15.8 & (12.6 to 19.5$)$ & 19 & 16.0 & (10.5 to23.6) \\
\hline $\begin{array}{l}\text { I am a serious football player, training and } \\
\text { competing to be the best I can be. }\end{array}$ & 74 & 13.5 & (10.9 to 16.6$)$ & 61 & 14.2 & (11.2 to 17.8$)$ & 13 & 10.9 & $(6.5$ to 17.8$)$ \\
\hline $\begin{array}{l}\text { I like the social side of the game. I want to have } \\
\text { fun with my friends. }\end{array}$ & 60 & 10.9 & (8.6 to 13.8$)$ & 46 & 10.7 & (8.1 to 13.9$)$ & 14 & 11.8 & (7.1 to 18.8$)$ \\
\hline Other & 50 & 9.1 & (7.0 to 11.8$)$ & 44 & 10.2 & (7.7 to 13.4$)$ & 6 & 5.0 & (2.3 to 10.6$)$ \\
\hline Missing & 3 & & & 0 & & & 3 & & \\
\hline \multicolumn{10}{|l|}{ Games played in 2014} \\
\hline Less than 10 & 188 & 35.4 & (31.5 to 39.6$)$ & 153 & 35.5 & (31.1 to 40.1 ) & 35 & 35.0 & (26.4 to 44.7$)$ \\
\hline 10 or more & 333 & 62.7 & (58.5 to 66.7 ) & 270 & 62.6 & (58.0 to 67.1 ) & 63 & 63.0 & (53.2 to 71.8$)$ \\
\hline I don't remember, other & 10 & 1.8 & (1.0 to 3.4$)$ & 8 & 1.9 & (0.9 to 3.6$)$ & 2 & 2.0 & (0.6 to 7.0$)$ \\
\hline Missing & 22 & & & 0 & & & 22 & & \\
\hline \multicolumn{10}{|l|}{ Pre-season training participation } \\
\hline Yes & 441 & 83.1 & (79.6 to 86.0$)$ & 362 & 84.0 & (80.2 to 87.2 ) & 79 & 79.0 & (70.0 to 85.8 ) \\
\hline No & 80 & 15.1 & (12.3 to 18.4$)$ & 61 & 14.2 & (11.2 to 17.8$)$ & 19 & 19.0 & (12.5 to 27.8 ) \\
\hline I don't remember, other & 10 & 1.8 & (1.0 to 3.4$)$ & 8 & 1.9 & (0.9 to 3.6$)$ & 2 & 2.0 & (0.6 to 7.0$)$ \\
\hline
\end{tabular}

$\omega$ 
Table 1 Continued

\begin{tabular}{|c|c|c|c|c|c|c|c|c|c|}
\hline & \multicolumn{3}{|c|}{ All players $(n=553)^{\star}$} & \multicolumn{3}{|c|}{ Injured $(n=431)$} & \multicolumn{3}{|c|}{$\begin{array}{l}\text { Non-injured or not stated } \\
(n=122)^{*}\end{array}$} \\
\hline & $\bar{n}$ & Per cent & $95 \% \mathrm{Cl}$ & $\overline{\mathbf{n}}$ & Per cent & $95 \% \mathrm{Cl}$ & $\mathrm{n}$ & Per cent & $95 \% \mathrm{Cl}$ \\
\hline Missing & 22 & & & 0 & & & 22 & & \\
\hline \multicolumn{10}{|c|}{ Weekly training sessions in 2014} \\
\hline 1 & 99 & 18.6 & (15.6 to 22.2 ) & 75 & 17.4 & (14.1 to 21.3 ) & 24 & 24.0 & (16.7 to 33.2$)$ \\
\hline 2 & 370 & 69.7 & (65.6 to 73.4$)$ & 306 & 71.0 & (66.5 to 75.1$)$ & 64 & 64.0 & (54.2 to 72.7$)$ \\
\hline 3 or more & 46 & 8.7 & $(6.6$ to 11.4$)$ & 39 & 9.0 & (6.7 to 12.1$)$ & 7 & 7.0 & (3.4 to 13.8 ) \\
\hline I didn't train & 16 & 3.0 & (1.9 to 4.8 ) & 11 & 2.6 & (1.4 to 4.5$)$ & 5 & 5.0 & (2.2 to 11.2 ) \\
\hline Missing & 22 & & & 0 & & & 22 & & \\
\hline
\end{tabular}

Table 2 Number and proportion of self-reported worst injuries by body region and injury type $(n=431)^{\star}$ for respondents from senior women's Australian football

\begin{tabular}{|c|c|c|c|c|c|c|c|c|c|}
\hline Body region† & Superficial & Fracture & Joint & Muscle & Concussion & Other‡ & Total & Total (\%) & $95 \% \mathrm{Cl}$ \\
\hline Lower limb & 15 & 18 & 127 & 69 & - & 6 & 235 & 54.5 & (49.8 to 59.2 ) \\
\hline Upper limb & 2 & 38 & 59 & 8 & - & 4 & 111 & 25.8 & (21.9 to 30.1 ) \\
\hline Face, head, neck & 2 & 2 & 2 & 1 & 25 & 3 & 35 & 8.1 & (5.9 to 11.1$)$ \\
\hline Trunk & 4 & 5 & 6 & 16 & - & 8 & 39 & 9.0 & (6.7 to 12.1 ) \\
\hline Other & 1 & 0 & 0 & 0 & - & 11 & 12 & 4.9 & (3.2 to 7.3$)$ \\
\hline Total & 24 & 63 & 194 & 94 & 25 & & & - & - \\
\hline Total (\%) & 5.6 & 14.6 & 45.0 & 21.8 & 5.8 & 7.2 & - & - & - \\
\hline $95 \% \mathrm{Cl}$ & (3.8 to 8.2 ) & (11.6 to 18.3$)$ & (40.4 to 49.7$)$ & (18.2 to 26.0$)$ & (4.0 to 8.4 ) & (5.1 to 10.0$)$ & - & - & - \\
\hline
\end{tabular}


limb injuries resulted in at least one missed game, with $17 \%$ leading to more than six missed games. Similarly, $63 \%$ of lower limb injuries resulted in at least 1 week of training being missed.

The worst injury sustained for the season was to the upper limb for $26 \% \quad(n=111)$ of injured respondents, nearly all involving the hand/fingers/thumb $(62 \%)$ or shoulder (26\%). Specifically, for the finger/thumb, these injury types included fractures $(n=28,6 \%$ of all injuries), ligament tears/sprains $(n=18)$ and dislocations $(\mathrm{n}=11)$, and, for the shoulder, dislocations $(\mathrm{n}=11,3 \%$ of all injuries) and ligament tear/strains $(\mathrm{n}=8)$. Half $(51 \%)$ of all upper limb injuries led to at least one missed game and $48 \%$ to at least 1 week of missed training.

Twenty-five cases of concussion (6\% of all injuries) were self-reported as the worst injury, all of which occurred during matches. Following the concussion, 11 (44\% of all reported concussions) players did not miss any games, 7 (28\%) missed 1 game and 7 (28\%) missed 2-3 games. Eleven people with concussion were treated in hospital, eight by a general practitioner/family doctor and eight by a sports trainer/physio (table 3 ).

Table 3 outlines the 600 treatments reported for the 431 worst injuries. In summary, $27 \%$ required treatment from a local physiotherapist and $18 \%$ required specialist treatment at a hospital by a surgeon or a sports medicine specialist.

Players were asked why they considered the reported injury to be their worst for the 2014 season. The most commonly collected responses were: I could not play at my best (27\%), the injury caused a lot of pain (23\%), I required medical treatment $(22 \%)$, the injury meant I missed games/training (16\%) and other (12\%). The 'other' reasons listed included financial costs relating to surgery, missed work, functional impairment and the injury causing the end of their playing career.

\section{DISCUSSION}

There have been no injury studies conducted for women in $\mathrm{AF}$, so it is not known if the current best practice for injury prevention, developed from the men's game, is also relevant for women. Therefore, this project was designed to address stage 1 of the Translating Research into Injury Prevention Practice (TRIPP) framework to gain a first understanding of AF injuries sustained by women. ${ }^{16}$ An overview of selfreported worst injuries sustained in the 2014 season (ie, maximum of 6-month recall period) was presented with ankle and knee ligament tears/sprains and finger/ thumb/hand injuries being the most commonly reported. These injuries had a substantial impact on players in terms of impaired participation, pain, missed games/training and requiring medical treatment.

\section{Lower limb injuries}

Lower limb joint damage was the most common of the broad injury types reported by women in this survey, as is also common in men's $\mathrm{AF}^{2-4} \mathrm{~A}$ considerable amount of the AF injury literature has focused on knee injuries, owing to the high treatment burden associated with injuries to this joint. ${ }^{1}$ The proportion of knee injuries was $14 \%$ in our study, which is reasonably consistent with reports from men's prospective community football surveys (ranging from $11 \%$ to $15 \%)^{3}$ and more broadly, from studies focused on medical treatment (ranging from $5 \%$ to $31 \%$ ). ${ }^{1}$

Anterior cruciate ligament (ACL) injuries in particular are of interest in other football codes and the subject of substantive literature, where, conservatively, the ACL injury rate has been estimated to be 2-3 times higher in women than men in contact/collision sports. ${ }^{11} 13 \quad 17$ While a similar gender differences for ACL injury might be expected in AF, this needs to be confirmed in future investigations as we were not able to collect data with diagnostic accuracy or in relation to participation exposure. Certainly, the priority of preventing AF-related knee injuries in men appears likely to be equal, if not greater, for women.

Muscle injuries comprised $22 \%$ of the injuries reported in our survey. Studies in men's AF have

Table 3 Treatment required for the self-reported worst injuries sustained by 431 respondents from senior women's Australian football

\begin{tabular}{|c|c|c|c|c|c|c|c|c|}
\hline & \multicolumn{2}{|l|}{$\begin{array}{l}\text { Upper limb } \\
(n=144)^{\star}\end{array}$} & \multicolumn{2}{|c|}{$\begin{array}{l}\text { Lower limb } \\
(n=353)^{\star}\end{array}$} & \multicolumn{2}{|c|}{ Other $(n=103)^{\star}$} & \multicolumn{2}{|c|}{ Total $(n=600)^{\star}$} \\
\hline & Per cent $†$ & (n) & Per cent† & (n) & Per cent† & (n) & Per cent $†$ & (n) \\
\hline No treatment & 1 & (2) & 2 & (6) & 2 & (2) & 2 & $(10)$ \\
\hline Self-treated & 15 & (21) & 16 & (56) & 8 & (8) & 14 & (85) \\
\hline Club trainer/physiotherapist & 15 & (22) & 18 & $(62)$ & 23 & (24) & 18 & $(108)$ \\
\hline General practitioner & 23 & (33) & 13 & $(46)$ & 22 & (23) & 17 & (102) \\
\hline Hospital/surgery/specialist & 24 & (34) & 16 & (55) & 18 & (19) & 18 & (108) \\
\hline Local physiotherapist & 18 & (26) & 33 & $(115)$ & 20 & (21) & 27 & (162) \\
\hline Other therapist $\ddagger$ & 4 & (6) & 4 & (13) & 6 & (6) & 4 & (25) \\
\hline
\end{tabular}


consistently reported muscle and tendon strains (particularly to the hamstring or groin) as having a high prevalence, accounting for $10-27 \%$ of injury types in community-level prospectively collected injury studies. ${ }^{3}$ Recent reviews of groin injury incidence and hamstring injury incidence in team sports show rates are approximately 2-3 times higher in men compared with women. ${ }^{18-20}$ Lower limb muscle strains were closer to having an equivalent proportion in men and the women from our sample.

\section{Upper limb injuries}

A quarter of all reported injuries involved the upper limb. Of these, more than half were wrist, hand or finger injuries, consisting of dislocations, fractures and sprains. From studies in Gaelic football (a sport with similarities to $\mathrm{AF}$ in terms of the required ball handling skills), women have a relatively high proportion of finger fractures, while men tend to sustain more shoulder injuries. ${ }^{21-23}$ Finger, hand and wrist injuries are common in men's AF, comprising $11-31 \%$ of medically treated injuries, often being a fracture/dislocation. ${ }^{1}$ Whether the likelihood of injury is different between men and women who play $\mathrm{AF}$ is unclear. There is certainly a medical burden from these upper limb injuries and many players missed at least 1 week of training/games.

\section{Concussion}

The proportion of worst injuries reported as concussions in the survey was $6 \%$. By comparison, studies in men's $\mathrm{AF}$ have reported that concussions account for $3-4 \%$ of all injuries. ${ }^{24-27}$ Differences in the incidence and outcome of concussion by sex have been extensively investigated. ${ }^{28-30}$ In sports where the rules of play are the same for men and women (ie, soccer and basketball), there is a consistently higher incidence of concussion in women than men. ${ }^{10} 31-33$ It has also been suggested that the outcomes following a concussion may be more severe for women than men, including a greater decline in reaction times, more symptoms and an increased chance of cognitive impairment. ${ }^{12} 3435$ Almost half of all cases of concussion in our survey reported that they did not miss any games, raising questions of an overly cautious approach in initial head injury diagnosis. However, $76 \%$ of respondents reporting a concussion also reported that they sought treatment in hospital or by a general practitioner. Clearly, the injury was important to the health of these players, given both the number of injuries and nature of treatment sought.

\section{Treatment required}

The number of missed games and the treatments required by women for $\mathrm{AF}$ injuries suggest that the reported injuries are a burden to the individual's health and to the healthcare system. Similar to previous population-based surveys, ${ }^{36}$ physiotherapists and general practitioners were the major sources of sports injury treatment. The proportion of hospital-based treatment in our survey, at $18 \%$, was substantially higher than has previously been reported from general population surveys ${ }^{36}$ but this is perhaps to be expected as our study focused on worst injuries, not all injuries.

\section{Strengths and limitations}

The retrospective nature of the survey questions was useful to gain a first profile of AF injuries in women. The sample represented $11 \%$ of senior women participants from all parts of the country at differing levels of play and experience. The data were collected relatively quickly and inexpensively across Australia to provide a nationwide overview of the problem. However, as the survey was only completed by women participating in senior leagues, findings are not immediately generalisable to the junior girls AF community (players aged $<17$ years). Further, to limit known recall bias, ${ }^{37} 38$ only details on the players' worst injury for the season were included, thereby introducing a reporting bias towards more severe injuries. All injuries were self-reported, with no medical confirmation possible. Although it was made clear that both injured and uninjured players should complete the survey, it is possible that women who were injured in the 2014 season had more interest in the outcomes of the study and were therefore more likely to respond, therein presenting an overestimate of injured versus non-injured respondents. Finally, exposure to injury (ie, time spent playing and training) was not recorded, so rates of injury could not be calculated.

\section{CONCLUSIONS}

While the FootyWISE survey provides valuable new insight into some of the worst $\mathrm{AF}$ injuries sustained by women, the results emphasise the need for a comprehensive prospective injury surveillance system to provide robust data to inform the development and monitoring of injury prevention measures. It will only be with a detailed understanding of the injuries sustained by women playing $\mathrm{AF}$, and the causes of these injuries, that the most effective injury prevention measures to prevent them can be determined.

Twitter Follow Lauren Fortington at @|fortington, Caroline Finch @CarolineFinch, Alex Donaldson @AlexDonaldson13

Acknowledgements The authors thank the Female Football State Managers from the AFL for assistance in disseminating the survey and appreciate the specific efforts of Jan Cooper, Female Football Development Manager, in all stages of the project. Finally, the authors thank all players who took time to participate in the survey.

Funding The FootyWISE study was funded by the Australian Football League (AFL) Research Board. Caroline Finch is funded by a National Health and Medical Research Council (NHMRC) Principal Research Fellowship (ID1058737). ACRISP is one of the International Research Centres for the Prevention of Injury and Protection of Athlete Health supported by the International Olympic Committee (IOC).

Disclaimer The AFL had no input to the conduct of the study or interpretation of results.

Competing interests None declared. 
Ethics approval Federation University Human Research Ethics Committee (A14-083)

Provenance and peer review Not commissioned; internally peer reviewed.

Data sharing statement No additional data are available.

Open Access This is an Open Access article distributed in accordance with the Creative Commons Attribution Non Commercial (CC BY-NC 4.0) license, which permits others to distribute, remix, adapt, build upon this work noncommercially, and license their derivative works on different terms, provided the original work is properly cited and the use is non-commercial. See: http:// creativecommons.org/licenses/by-nc/4.0/

\section{REFERENCES}

1. Ekegren CL, Gabbe BJ, Finch CF. Medical-attention injuries in community Australian football: a review of 30 years of surveillance data from treatment sources. Clin J Sports Med 2015;25:162-72.

2. Orchard JW, Seward H, Orchard JJ. Results of 2 decades of injury surveillance and public release of data in the Australian Football League. Am J Sports Med 2013;41:734-41.

3. Finch CF, Gabbe B, White P, et al. Priorities for investment in injury prevention in community Australian football. Clin J Sport Med 2013;23:430-8.

4. Andrew N, Gabbe BJ, Cook J, et al. Could targeted exercise programmes prevent lower limb injury in community Australian football? Sports Med 2013;43:751-63.

5. Donaldson A, Cook J, Gabbe B, et al. Bridging the gap between content and context: establishing expert consensus on the content of an exercise training program to prevent lower-limb injuries. Clin $J$ Sports Med 2015;25:221-9.

6. Finch CF, Twomey DM, Fortington LV, et al. Preventing Australian football injuries with a targeted neuromuscular control exercise programme: comparative injury rates from a training intervention delivered in a clustered randomised controlled trial. Inj Prev 2016;22:123-8.

7. Orchard J, McCrory $\mathrm{P}$, Makdissi M, et al. Use of rule changes to reduce injury in the Australian Football League. Minerva Ortop Trauma 2014;65:355-64.

8. Australian Football League. 118th Annual Report 2014. http://www. afl.com.au/afl-hq/annual-reports (accessed 11 Nov 2015).

9. Australian Football League. Concussion. Secondary Concussion. 2015 Available from http://www.aflcommunityclub.com.au/index.php? id=66 (accessed 11/11/2015).

10. Hootman JM, Dick R, Agel J. Epidemiology of collegiate injuries for 15 sports: summary and recommendations for injury prevention initiatives. J Athl Train 2007;42:311-19.

11. Prodromos CC, Han $\mathrm{Y}$, Rogowski J, et al. A meta-analysis of the incidence of anterior cruciate ligament tears as a function of gender, sport, and a knee injury-reduction regimen. Arthroscopy 2007:23:1320-5.e6.

12. Broshek DK, Kaushik T, Freeman JR, et al. Sex differences in outcome following sports-related concussion. $J$ Neurosurg 2005;102:856-63.

13. Beynnon BD, Vacek PM, Newell MK, et al. The effects of level of competition, sport, and sex on the incidence of first-time noncontact anterior cruciate ligament injury. Am J Sports Med 2014;42:1806-12.

14. DiMartino K. Survey of the prior training and playing loads of first year AFL players [honours thesis]. University of Ballarat, 2010.

15. Australian Sports Injury Data Working Party. Australian Sports Injury Data Dictionary: guidelines for injury data collection and classification for the prevention and control of injury in sport and recreation. SportSafe Australia (Australian Sports Commission) and
Sports Medicine Australia. 1998. http://sma.org.au/wp-content/ uploads/2009/12/datadictionary.pdf

16. Finch C. A new framework for research leading to sports injury prevention. J Sci Med Sport 2006;9:3-9.

17. Waldén $\mathrm{M}$, Hägglund $\mathrm{M}$, Magnusson $\mathrm{H}$, et al. Anterior cruciate ligament injury in elite football: a prospective three-cohort study. Knee Surg Sports Traumatol Arthrosc 2011;19:11-19.

18. Waldén M, Hägglund M, Ekstrand J. The epidemiology of groin injury in senior football: a systematic review of prospective studies. Br J Sports Med 2015;49:792-7.

19. Cross KM, Gurka KK, Saliba S, et al. Comparison of hamstring strain injury rates between male and female intercollegiate soccer athletes. Am J Sports Med 2013;41:742-8.

20. Orchard JW. Men at higher risk of groin injuries in elite team sports: a systematic review. Br J Sports Med 2015;49:798-802.

21. Brown J, Papadopoulos C, Pritchett R. Examination of injury in female Gaelic football. Int J Exerc Sci 2013;6:98-105.

22. Crowley J, Jordan J, Falvey E. A comparison of Gaelic football injuries in males and females in primary care. Irish Med $J$ 2011;104:268-70.

23. O'Rourke KP, Quinn F, Mun S, et al. A comparison of paediatric soccer, Gaelic football and rugby injuries presenting to an emergency department in Ireland. Injury 2007;38:104-11.

24. Ekegren CL, Gabbe BJ, Donaldson A, et al. Injuries in community-level Australian football: results from a club-based injury surveillance system. J Sci Med Sports 2015;18:651-5.

25. Braham R, Finch CF, McCrory P. The incidence of head/neck/ orofacial injuries in non-elite Australian Football. J Sci Med Sports 2004;7:451-3.

26. Gabbe B, Finch $\mathrm{C}$, Wajswelner $\mathrm{H}$, et al. Australian football: injury profile at the community level. J Sci Med Sports 2002;5:149-60.

27. Fortington L, Twomey D, Finch C. Concussion in community Australian football-epidemiological monitoring of the causes and immediate impact on play. Inj Epidemiol 2015;2:690.

28. Abrahams S, Fie SM, Patricios J, et al. Risk factors for sports concussion: an evidence-based systematic review. $\mathrm{Br} J$ Sports Med 2014;48:91-7.

29. Noble JM, Hesdorffer DC. Sport-related concussions: a review of epidemiology, challenges in diagnosis, and potential risk factors. Neuropsychol Rev 2013;23:273-84.

30. Maher ME, Hutchison M, Cusimano M, et al. Concussions and heading in soccer: a review of the evidence of incidence, mechanisms, biomarkers and neurocognitive outcomes. Brain Inj 2014;28:271-85.

31. Covassin T, Elbin RJ, Crutcher B, et al. The management of sport-related concussion: considerations for male and female athletes. Trans/ Stroke Res 2013;4:420-4.

32. Dick RW. Is there a gender difference in concussion incidence and outcomes? Br J Sports Med 2009;43(Suppl 1):i46-50.

33. King NS. A systematic review of age and gender factors in prolonged post-concussion symptoms after mild head injury. Brain Inj 2014;28(13-14):1639-45.

34. Preiss-Farzanegan SJ, Chapman B, Wong TM, et al. The relationship between gender and postconcussion symptoms after sport-related mild traumatic brain injury. PM R 2009;1:245-53.

35. Berz K, Divine J, Foss KB, et al. Sex-specific differences in the severity of symptoms and recovery rate following sports-related concussion in young athletes. Phys Sports Med 2013;41:58-63.

36. Mitchell R, Finch C, Boufous S. Counting organised sport injury cases: evidence of incomplete capture from routine hospital collections. J Sci Med Sport 2010;13:304-8.

37. Gabbe BJ, Finch CF, Bennell KL, et al. How valid is a self reported 12 month sports injury history? Br J Sports Med 2003;37: $545-7$.

38. Valuri G, Stevenson M, Finch C, et al. The validity of a four week self-recall of sports injuries. Inj Prev 2005;11:135-7. 